\title{
Impact of Engineering Financial Market and Using Financial Derivatives on Financial Analysts Interest: Empirical Study from Amman Stock Exchange -Jordan
}

\author{
Mohammad Khalid Al Attar ${ }^{1}$ \\ ${ }^{1}$ Department of Banking, Faculty of Economics and Administrative Sciences, Al Zaytoonah University of \\ Jordan, Jordan \\ Correspondence: Mohammad Khalid Al Attar, Department of Banking, Faculty of Economics and Administrative \\ Sciences, Al Zaytoonah University of Jordan, Jordan. Tel: 962-785-383-893. E-mail: \\ dr_attarmohammad@yahoo.com
}

Received: July 2, 2016

doi:10.5539/ijef.v8n9p208
Accepted: July 25, 2016

Online Published: August 25, 2016

\begin{abstract}
This study aimed to measure the level of Amman Financial Market efficiency and show the role of financial derivatives in improving Markets' efficiency. Generally, financial derivatives are considered an essential source of financing an economy. In addition, diversification of financial derivatives' instruments which are circulated in a stock market as the main standard of measuring its development and efficiency, called as engineering. For the purpose of achieving the objectives of the study, the researcher selected some of the financial analysts' that represent institutions in Amman Stock Exchange in Jordan, to serve as the sample of the study. Simple Random Sampling was used to select the sample to represent the whole population. Furthermore, the researcher developed a questionnaire to judge the respondents opinions and test the validity of the hypotheses. The questionnaire was designed by using a five -point -Likert scale (strongly agree, agree, neutral, disagree, strongly disagree). In total, the researcher distributed 100 questionnaires and 85 were returned from the selected sample of the study ( $85 \%$ from the whole questionnaires distributed). Results of the study showed that there was a strong bond between financial derivatives and efficiency of Amman Stock Market. Moreover, findings indicated that there is a statistical significant sign between financial analysts' interests in returns of financial derivatives with their tools and efficiency of these markets.
\end{abstract}

Keywords: financial derivatives, financial markets' efficiency, financial analyst interest, Amman stock exchange

\section{Introduction}

As we live in the beginning of $21^{\text {st }}$ century now, it is widely believed that financial derivative engineering can provide an efficient assistance to achieve the strategic goals sought by businesses (Yadav, 2016). Financial Engineering is not only concerned with reducing the costs of operating activities, but it goes further as it develops and comes up with new financial instruments (Prabha, Savard, \& Wickramarachi, 2014). Moreover, it provides creative solutions for problems encountering businesses as it occurred to face risks that encounter those companies. This took place in the mid of 1980s when London banks established departments to help corporations to come across jeopardies caused by their clients and find solutions for those corporations.

It is worth to mention that creativity and foundation of Financial Engineering do not only rely on the new products it provides, but they extend to the endeavors of making use of old tools and ideas to serve businesses' goals. Derivatives are the foundation for most of the financial engineering of the last thirty-five years. Valuation and risk metrics for derivatives involve devilishly complex mathematics, but their structure is relatively straightforward. One need not be a "quant" to understand how they work and how they affect the efficiency of capital markets (Turbeville, 2013).

According to Katz (2011), for market to work, they need greater investor confidence in greater board oversight, supervision and Market development will depend on general institutions that includes regulations that prevent conflict of interest and fraud and that align the compensation package to top executives with the interest of the firm whose fate is entrusted to their hands. Financial engineering and derivatives usage produce efficiency in capital market, stock market and other basic market. Arguably, the single largest innovation in global financial 
markets over the past two decades has been the emergence and growth of derivative market (Gupta, 2004).

\section{Problem Statement}

Financial derivatives are deemed one of financial engineering's instruments based on different prospects of the investor (buyer) and the seller (writer) since each one of them expects contrary to the other and so those derivatives involve great risks resulted from not paying the total sum of investment at the time of agreement. Financial derivatives' risk includes credit, finance, market liquidity, and legal risks. Thus, insufficient knowledge to kinds of financial derivatives may lead many investors towards those risks and as a result bankruptcy of companies occurs (Finnerty, 1992). This can negatively affect stock markets' efficiency in general and financial derivatives markets in particular. It is worth to mention that the numerous banking problems occurred lately, belong to the financial derivatives products as newly banking innovations. Those problems are attached to the derivatives although they are used as covering tools for some of the financial centers and currencies to guard portfolios and several investments against frequent and great fluctuations in markets such as changes in interest rate or exchange rate (Ibraheem, 2013). Risk is potential if they were used for the previously mentioned purpose and became investment tools displayed and in demand in global stock markets for speculation and gain profit in the short term and thus they turned to be time bombs that explode ruin best institutions.

\section{Significance of Study}

The researcher believes that the importance of studying financial derivatives comes from the level of its impact on increasing stock markets' efficiency. Therefore, they are deemed significant factors at stock markets since they take into account movement of future prices for financial instruments such as currencies and options in addition to financial derivatives. In addition, financial derivatives contributed effectively to accelerating its revolution which led to Global Market phenomena. This phenomenon gave rise to rapid liberalization of global stock markets and removal of restrictions that curb financial institutions' activities and limit transmitting of capital, taking advantage from information technology revolution which is known as "Globalization". One should not forget the role of competition among financial institutions and its frequencies which led to compete with the newest financial instruments and supply them into the markets in addition to encouraging factors for investors and dealers to demand them.

\section{Questions of the Study}

The study aimed to answer the following questions which reflect the statement of the problem:

1) To what extent do Financial Derivatives contribute to achieve the sought levels of efficiency for stock markets?

2) How could Financial Derivatives' indicators be utilized to help financial analysts predict future prices which help them cover investment portfolios in the future?

3) Are the outcomes of Financial Derivative used as a general indicator for efficiency of stock markets? Could they be used as guidance for making different decisions?

\section{Objectives of the Study}

This paper aimed to focus on the financial derivatives and how to deal with them. In addition, it investigated their impact on stock markets and how they are used to improve their effectiveness and reflection on stock markets' efficiency.

It might be possible to adopt financial derivatives to affect efficiency of stock markets from other several scopes such as a tool for expecting prices (price of contracted securities at the current market on the due date). In addition to planning money flows when working in the conditions of full certainty, finding best opportunities for Speculation (Ibraheem, 2013). Derivatives also help in facilitating and activating assets under contract, accelerating the implementation of investment strategies. Meanwhile using the derivatives for the purpose of long -term investment represented in reserving these derivatives for a long time and encouraging local governments of derivatives markets as an element to attract foreign capital (Merton, 1995).

\section{Literature Review}

Stock markets are deemed some of the important newly innovated areas in transactions which include all channels where fund flows among different sectors and individuals. Stock markets can be defined as the places where financial assets are exchanged which means money flows into it from those anticipated savings to the invested units (Pattipeilohya, Enda, Tabbaea, Frosta, \& De Haan, 2013). Thus, money moves from units that have financial surplus; in sufficient investment opportunities as the derivatives (Abumustafa \& Al-Abduljader, 2011). Moreover, financial derivatives have witnessed a great concern in the last few years by investors and 
financial analysts at stock markets in the developing countries. In addition, it was empirically proven that those markets represent excellent investment opportunities and a factor that attracts local and foreign capital in those countries. Furthermore, efficiency of stock markets and their organization contribute positively towards creating comprehensive economic development. Without them, societies cannot get financial resources to finance and improve investment activities namely; those immense activities. Many countries try to improve their local markets in order to make an element that attracts foreign capital. Through those attempts, concentration is paid towards founding legal, institutive, and legal framework that contributes to increasing the amount and efficiency of local savings and expanding foreign investments at the same time.

Lakshmi (2014) clarified that both financial derivatives market and capital market are identified with one another and give moment response as the development in one accord. It was likewise discovered that financial derivatives aides in controlling the financial risk and managing to develop the economy. Girish (2012) had examined the impact of derivatives trading on stock market unpredictability. I was observed that there is no huge change in the volatility to some degree. Srinivasan, Mathew and Davidson (2012) had examined the effect on the spot stock market volatility due to the introduction of futures market in India for the period from 1995 to 2011. The result shows that there is a significant decrease in the domestic market volatility due to the introduction of derivatives trading. This indicates that the index futures play a significant role in decreasing the volatility of the stock market and in turn also contribute to increase in the stock market efficiency.

Financial Engineering is the emergence of a new funding pattern differs from the traditional funding in vision of the risk levels in investments need funding. That type of funding becomes important when the accumulative capital decreases (Doyle et al., 2010). Financial engineering provided new financing resources; thus, have provided opportunities to Companies to design instruments which could give them the freedom to address the varying needs of investors group and to lower the cost of capital. Financial engineers often helped upon to develop new instrument to secure the fund necessary for the operation of large scale businesses (Ibreheem, 2013).

\subsection{Elements of the Problem of the Study}

The study aimed to answer the following questions:

\subsubsection{First Main Question}

Is there an effect of the efficiency of ASE on the financial analysts' interest?

\subsubsection{Second Main Question}

Is there an effect of the efficiency of ASE on the type of derivatives in ASE?

\subsubsection{Third Main Question}

Is there an effect of the type of derivatives in ASE on the financial Analysts' interest?

\subsubsection{Fourth Main Question}

Is there a mediating effect of the type of derivatives on the relationship between the efficiency of ASE and the financial analysts' interest?

\subsection{Hypotheses}

1) First main hypothesis (H0): There is no significant statistical relationship between the financial analysts' interests and efficiency of ASE.

2) Second main hypothesis (H0): There is no significant statistical relationship between the type of Financial Derivatives and the efficiency of ASE.

3) Third main hypothesis (H0): There is no significant statistical relationship between the type of Financial Derivatives and the financial analysts' interest.

4) Fourth main hypothesis (H0): Type of financial derivatives mediates the relationship between the efficiency of ASE and the financial analysts' interest in the market.

\subsection{Model of the Study}

After reviewing studies addressed this topic and in the light of the objectives of the current study, variables of the study were specified and represented as follows and stated in Figure 1:

\section{Independent Variables}

Efficiency of Market: Capital markets are grounded in the belief that competition among profit-seeking market 
participants will ensure that asset prices continuously adjust to reflect all publicly available information (Fama, 1970).

\section{Mediating Variable}

Financial Derivatives: Are financial instruments in the form of contracts between two parties to engage in a transaction at a future time. The value of the contract is derived from the value of an underlying asset (e.g., equity, bond, or commodity) or market variable (e.g., interest rate, exchange rate, stock index, or credit risk). The notional amounts of a derivative contract refer to the principal value of the underlying asset. (Prabha, Savard, $\&$ Wickramarachi, 2014).

\section{The Dependent Variable}

Financial Analysts' Interest: Analyst interest predicts future fundamental changes, capital market activities, and future stock returns, and is a type of moral hazard problem that occurs when a person or institution has multiple objectives (interests) and as a result has conflicts between them, may be responsible for the recent scandals (Michaely \& Womack, 1999).

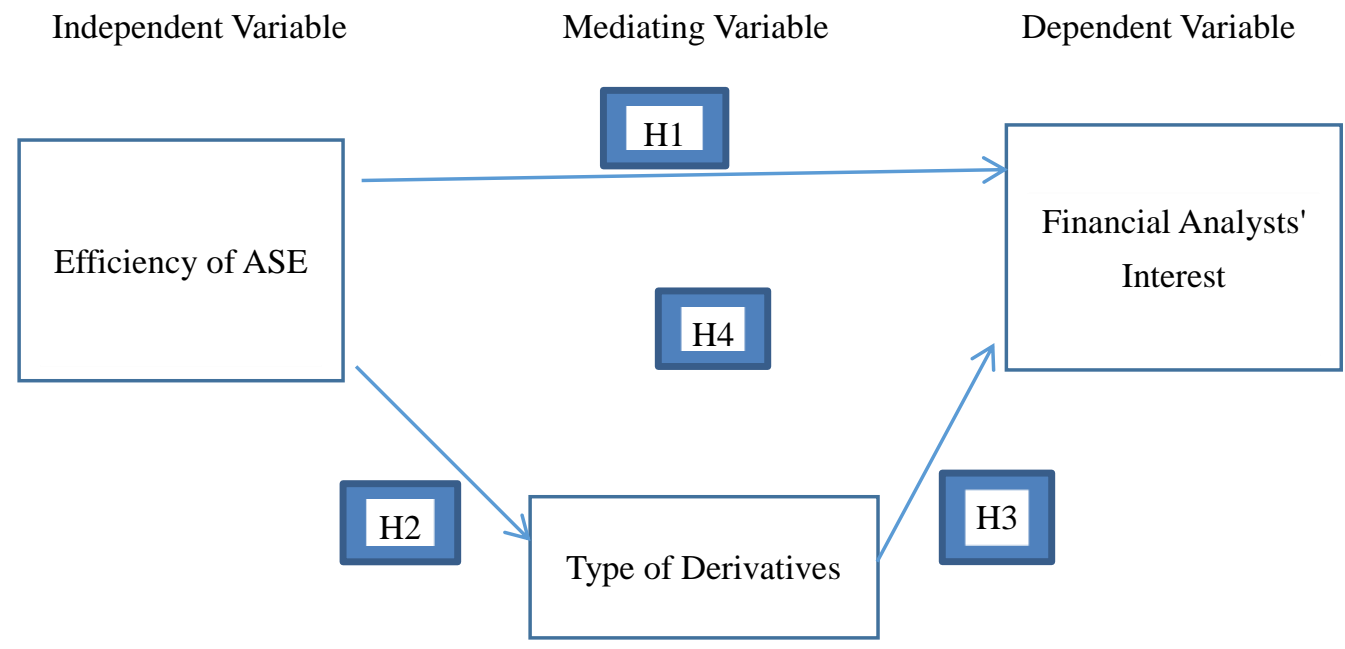

Figure 1. Theoretical framework

\section{Research Method}

\subsection{Methodology}

The research was carried out by primary data, collected by using a structured questionnaire. In terms of purpose, this study can be useful for an extensive range of users including stockholders, financial analysts, and other stakeholders. Information was collected through the questionnaire distributed to financial analysts' interested in Amman-stock exchange and the data was analyzed by using SPSS 22 software.

\subsection{Sample and Statistical Population}

The statistical population in this study included companies' financial analysts' in Amman-Stock Exchange. The questionnaire was distributed among 100 financial analysts', and 85 were recollected.

\section{Results and Findings}

The reliability coefficient presented by alpha showed a degree of $(0.75)$, a percentage considered suitable for the objectives of the current study.

\subsection{Descriptive Statistic Results}

Results showed, in Table 1 that the largest age percentage is 53\%, representing the ages between 31-35 years. However, the lowest categories of the ages of the sample were 20-25 and 46-50 which stood at 5.9\% per each. The tale showed that $88 \%$ of the sample was males while $12 \%$ females. However $18 \%$ of respondents were single while $82 \%$ married. Table 4 illustrated that the bachelor degree holders form $70 \%$ of the total members of the sample whereas master and $\mathrm{PhD}$ holders were the lowest and represent a 5.9\% only. Years of experience from 
5-10 were the highest and form $66 \%$ of the sample of the study whereas $17 \%$ of the experience was less than five-year experience. Moreover, it is indicated that $17 \%$ of the respondents, which is the lowest percentage, have experience that ranges between 11-15 years.

Table 1. Descriptive statistics (demographic characteristics)

\begin{tabular}{llll}
\hline Demographic variable & Type of independent variable & Value & Percentage \\
\hline Age & $20-25$ & 5 & 0.059 \\
& $26-30$ & 10 & 0.11 \\
& $31-35$ & 45 & 0.53 \\
& $36-40$ & 10 & 0.11 \\
& $41-45$ & 10 & 0.11 \\
& $46-50$ & 5 & 0.059 \\
\hline Gender & Male & 75 & 0.88 \\
& Female & 10 & 0.12 \\
\hline Marital Status & Single & 15 & 0.18 \\
& Married & 70 & 0.82 \\
\hline Education Level & Diploma & 15 & 0.176 \\
& Bachelor Degree & 60 & 0.70 \\
& Master's degree & 5 & 0.059 \\
& PHD & 5 & 0.059 \\
\hline Experience & $0-5$ & 15 & 0.17 \\
& $6-10$ & 55 & 0.66 \\
& $11-15$ & 15 & 0.17 \\
\hline Total & & 85 & $100 \%$ \\
\hline
\end{tabular}

What Is the Correlation between the efficiency of ASE on the type of derivatives and Financial Analysts' interest in the Market?

Pearson correlation is used to answer such a question as in Table 2, and for scientific research a correlation of 0.866 and 0.768 for both type of derivatives and financial analysts interest respectively, results showed a strong relationship between the dependent and independent variables, but results were even better and the correlation appeared at a level of 0.000 significance, for both dependent variables.

Table 2. Pearson correlation

\begin{tabular}{lcll}
\hline Type of variables & Type of derivatives & Financial Analyst Interest & Mediating \\
\hline Efficiency of ASE(Pearson) & 0.866 & 0.768 & 0.721 \\
Efficiency of ASE (correlation) & $0.000^{*}$ & $0.000^{*}$ & $0.004^{*}$ \\
\hline
\end{tabular}

Note. * Significant at a level of 0.01 .

What Is the Correlation between the type of derivatives and Financial Analysts' interest in the Market?

As illustrated in Table 3 the correlation between the variables was 0.803 , with a positive significant relation.

Table 3. Pearson correlation

\begin{tabular}{lc}
\hline Type of variables & Financial Analyst Interest \\
\hline Type of derivatives (Pearson) & 0.803 \\
Type of derivatives (correlation) & $0.000^{*}$ \\
\hline
\end{tabular}

Note. * Significant at a level of 0.01 .

\subsection{Hypotheses Testing Results}

The value of calculated (t) for the hypotheses $(\mathrm{H} 1)(\mathrm{H} 2),(\mathrm{H} 3)$ and $(\mathrm{H} 4)$ with the significance level of $(0.00)$ were higher than the tabulated $(t)$ value $(\alpha=0.01)$. All the hypothesis were rejected indicating a relationship between the variables. As in Table 4. 
Table 4. Testing hypotheses based on the use of t-test

\begin{tabular}{lllll}
\hline Hypothesis & $\mathrm{H} 1$ & $\mathrm{H} 2$ & $\mathrm{H} 3$ & $\mathrm{H} 4$ \\
\hline Significance & $0.004^{*}$ & $0.000^{*}$ & $0.000^{*}$ & $0.048^{* *}$ \\
\hline
\end{tabular}

Note. * Significant at a level of 0.01 .

**Significant at a level of 0.05 .

Results from the single regression indicated a statistical positive relationship between the financial derivatives and efficiency of ASE, and a positive statistical relationship between efficiency and type of derivatives, in addition to the relationship between the type of derivatives and financial analysts' interest in the market. The study also mediated the type of derivatives and a positive relationship was also revealed.

\section{Recommendations and Limitations}

In light of the above, the researcher finds it important to pinpoints the following points regarding aspects of dealing with financial derivatives' tools so as to study the market and its efficiency and reduce limitations. For it is a must to clearly and precisely set the goals for dealing with these derivatives. The derivatives should be managed in a way that goes in line with the method of managing risks and avoid the occurrence of risks that affect markets. Policies of employing the derivatives should go hand in hand with the changes of an institution and market conditions.

There is a need to measure revenues of the derivatives regularly and in details so as to limit risks and achieve the goals. There is a need to assess dealers' portfolios on the basis of price rate taking into consideration their private costs and selecting a cohesive standard to estimate derivatives markets' risks and compare them to the traditional investment risks namely; price, changes, correlative coefficient, discount price, and the extent of variation between actual and expected fluctuations. There is a need for regular and precise prediction of the amount of the demanded money for investing in the derivatives and identify the surplus.

\section{References}

Abumustafa, N., \& Al-Abduljader, S. (2011). Investigating the implications of derivative securities in emerging stock markets: The Islamic perspective. Journal of Derivatives \& Hedge Funds, 17(2), 115-121. http://dx.doi.org/10.1057/jdhf.2010.7

Doyle, B., Mefford, R., \& Tay, N. (2010). What Financial Risk Managers Can Learn from Six Sigma Quality Programs. Finance. Paper 2. Retrieved on Feb.19. 2016 from http://repository.usfca.edu/fe

Fama, E. F. (1970). Efficient Capital Markets: A Review of Theory and Empirical Work. The Journal of Finance, 25(2). Papers and Proceedings of the Twenty Eighth Annual Meeting of the American Finance Association. http://dx.doi.org/10.2307/2325486

Finnerty, J. (1992). An Overview of Corporate Securities Innovation. Journal of Applied Corporate Finance, (Winter), 23-39. http://dx.doi.org/10.1111/j.1745-6622.1992.tb00215.x

Girish, G. P. (2012). GARCH Model to study the effect of introduction of derivatives trading on stock market volatility of National Stock Exchange (NSE) India. JM International Journal of Finance (JMIJF), 2(3), 61-70.

Gupta, R. (2004). Derivatives Markets and Real Economic Activity. PhD dissertation, Victoria University.

Ibraheem, H. (2013). Mechanisms of Financial Engineering as New Alternatives. International Refereed Research Journal, IV(3), 21-40.

Lakshmi., B. (2014). Performance of financial derivatives (Futures) in Indian capital market. International Journal of Innovative Technology and Adaptive Management (IJITAM), 1(5), 2347-3622.

Merton, R. (1995). Financial Innovation and the Management and Regulation of Financial Institutions. Journal of Banking and Finance, 19, 461-481. http://dx.doi.org/10.1016/0378-4266(94)00133-N

Michaely, R., \& Womack, K. (1999). Conflict of Interest and the Credibility of Underwriter Analyst Recommendations. The Review of Financial Studies, 12(4), 653-686. http://dx.doi.org/10.1093/rfs/12.4.653

Pattipeilohya, C., Enda, V., Tabbaea, M., Frosta, J., \& De Haan, J. (2013). Unconventional monetary policy of the ECB during the financial crisis: An assessment and new evidence. DNB working papers, 381, version 22. The Netherlands. http://dx.doi.org/10.2139/ssrn.2278838

Prabha, A., Savard, K., \& Wickramarachi, H. (2014). Deriving the Economic Impact of Derivatives - Growth 
Through Risk Management. Published manuscript, Milken Institute.

Srinivasan, M., Mathew, J., \& Davidson, A. (2012). Repercussion of Futures Trading on Spot Market: Evidence from India. South East Asian Journal of Contemporary Business, Economics and Law, 1, 175-182.

Turbeville, W. (2013). Derivatives Innovation in the Era of Financial Deregulation. Financial Pipeline Series, part three, New York.

Yadav, S. (2016). Impact of derivatives trading on the volatility of stock market in India: A review. Asian Journal of Management Research, 6(3), 567-579.

\section{Copyrights}

Copyright for this article is retained by the author(s), with first publication rights granted to the journal.

This is an open-access article distributed under the terms and conditions of the Creative Commons Attribution license (http://creativecommons.org/licenses/by/4.0/). 